\title{
Vibrations induced by the passage of trains at various speeds and their effect on the structural response of buildings - an experimental and numerical analysis
}

\author{
Barbara Kożuch ${ }^{1, *}$, Filip Pachla ${ }^{1}$, and Tadeusz Tatara ${ }^{1}$ \\ ${ }^{1}$ Cracow University of Technology, Cracow, Poland
}

\begin{abstract}
This paper presents a selection of vibration measurement results and analyses performed with regard to their harmfulness to residential buildings. The first part of the paper refers to the analysis of railway vibrations measured in situ at the foundation level of residential building. These vibration records were then used to assess the harmfulness of vibrations relating to each train speed. Assessment of the vibration harmfulness of the building was performed with an indicator of the perceptibility of vibration through a structure (WODB), according to the Polish standard. The second part of the study refers to the creation of dynamic models of buildings with the use of the 'Diana' software program and analysis of their responses to railway vibrations. The thresholds specified by the standard in any of the train speeds of up to $250 \mathrm{~km} / \mathrm{h}$ were not exceeded. Nevertheless, propagation of vibrations induced by train passages and their effect on the structural response of buildings is a complex phenomenon. Without in situ measurements, it is hard to assess the impact of induced vibrations on buildings. As proven in the paper, a train moving on a track at various speeds does not uniformly make the vibration greater in each frequency band.
\end{abstract}

\section{Introduction and background}

It is well known that vibrations from railways do not have a positive impact on the surrounding area including infrastructure objects. This is a worldwide problem and has been considered in many papers (inter alia [1,2]). Therefore, before the authorisation for the use of the new Pendolino trains (EMU 250), approval and velocity tests were conducted in Poland. Part of the work has been published in articles [3-5]. The paper presents a selection of vibration measurement results and analyses performed with regard to their harmfulness to residential buildings. The trains were operating at predetermined speeds varying between 40 and $250 \mathrm{~km} / \mathrm{h}$. The measuring polygon and the arrangement of the sensors are presented in Fig. 1.

\footnotetext{
* Corresponding author: kozuchbm@gmail.com
} 


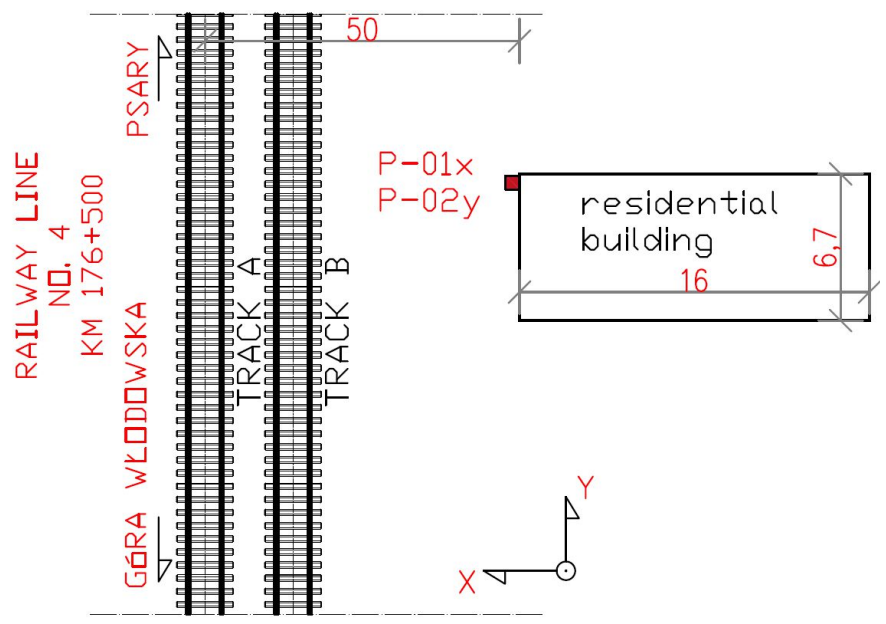

Figure 1. Measuring polygon - schematic arrangement of sensors

\section{In situ measurement and analysis}

Assessment of the harmfulness of vibration on the construction was performed according to Polish standard [6] using the indicator of the perceptibility of vibration through the construction (WODB). The indicator directly displays how many times the lowest limit consideration of dynamic influence on a structure has been exceeded. Values of WODB below 1 indicate that the vibrations do not adversely affect the building. The obtained WODB values were divided into two groups. For passages with speeds of up to $230 \mathrm{~km} / \mathrm{h}$, the highest values were selected for each frequency band. The whole analysis was compared with the values obtained from the passage of the train at a speed of 250 $\mathrm{km} / \mathrm{h}$. The results are presents in Fig. 2.

The vibration limits specified by the standard for any of the train passage speeds of up to $250 \mathrm{~km} / \mathrm{h}$ were not exceeded. However, increasing the speed leads to an increase in the destructive impact of the vibration on the examined structure. However, this does not happen uniformly in every one-third octave frequency band. For some frequencies (e.g. 12.5 and $16 \mathrm{~Hz}$ ), increasing the speed reduces vibrations. In addition, attention should be paid to frequency bands that are particularly sensitive to vibrations in these frequency bands.

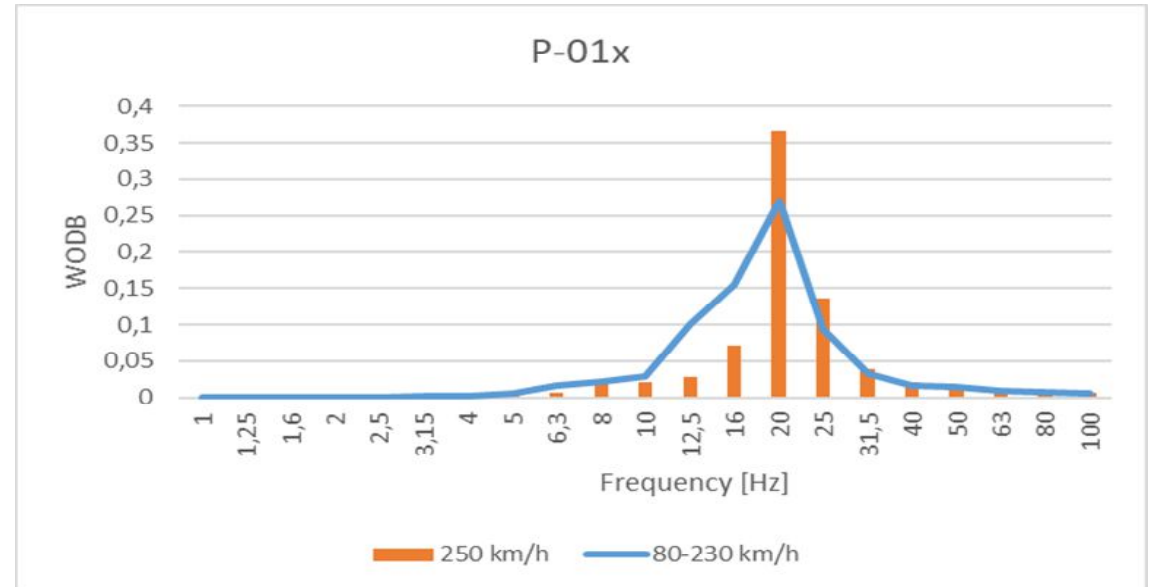

Figure 2a. WODB spectrum in one-third octave bands - Pendolino trains at a speed of $250 \mathrm{~km} / \mathrm{h}$ 


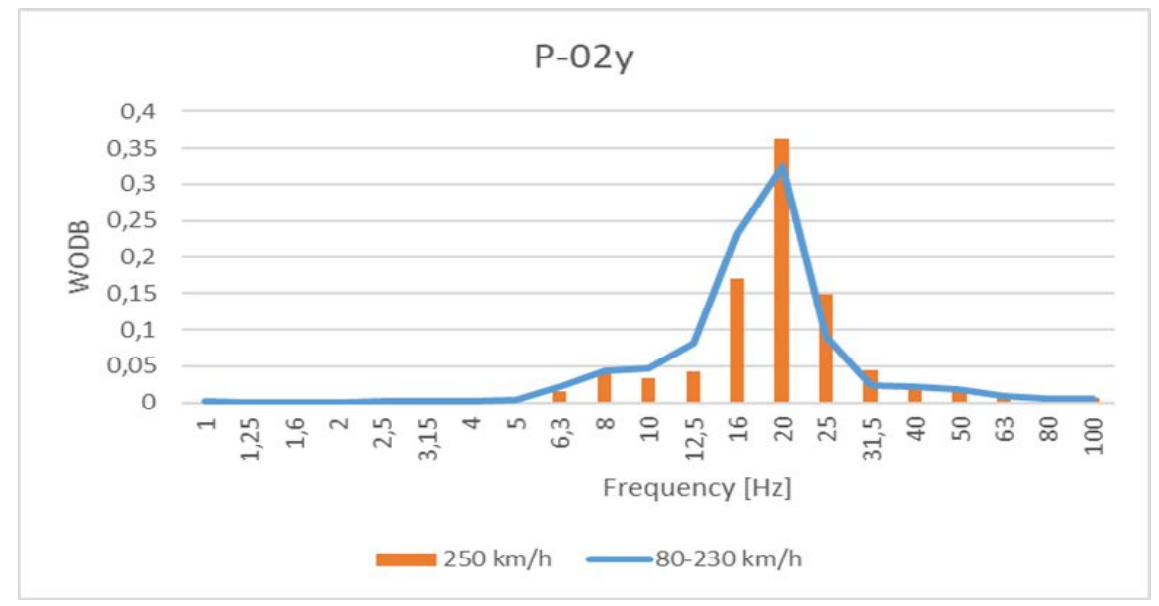

Figure 2b. WODB spectrum in one-third octave bands - Pendolino trains at a speed of $250 \mathrm{~km} / \mathrm{h}$

\section{FEA simulations}

A computational 2D FEA model was also created in this study. The model was prepared as a plane strain, using the 'Diana' FEA software. A general view of this model is presented in Fig. 3. Stiff boundary conditions were adopted at the bottom edge of the model; this is due to rock lying at a small depth. On the vertical edges, the area with absorbent abilities was modelled with PMLs (perfectly matched layers). A PM is an artificial absorbent layer for elastic waves used to truncate computational regions in FEM in order to simulate problems with open boundaries [7]. In Diana, the implementation of PML is entirely based on the work of Basu and Chopra $[8,9]$.

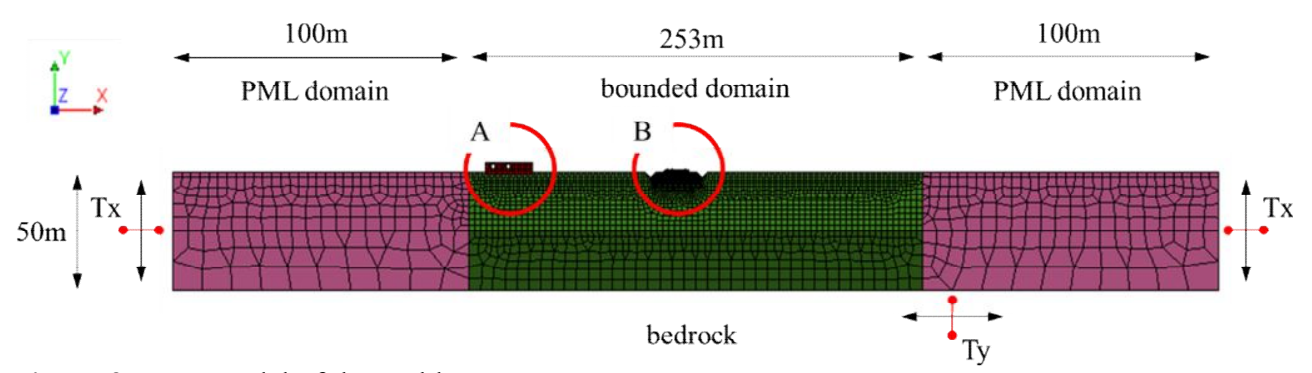

Figure 3. FEM model of the problem.

The structure of the track was modelled to a high level of detail. The building on the ground at distance of $50 \mathrm{~m}$ from the track was also modelled (see Fig. 4). Two different approaches were taken with regard to modelling the load. In the first approach, the loads were used to model the influence of the train, while in second approach, real in situ measured accelerations were used. 


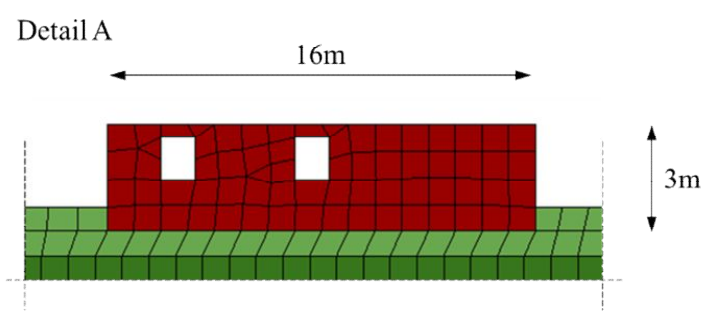

Figure 4. Detail A of the FEM model

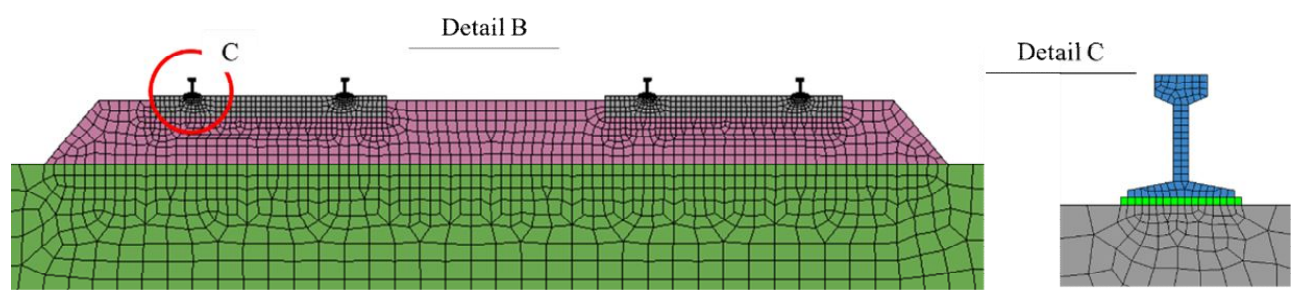

Figure 5. Details B and C of the FEM model

An example load curve from the first modelling approach with a train speed of $250 \mathrm{~km} / \mathrm{h}$ is presented in Fig. 6. The acceleration of the sleeper used to model the influence (recorded in situ, with a train speed of $250 \mathrm{~km} / \mathrm{h}$ ) is presented in Fig. 7.

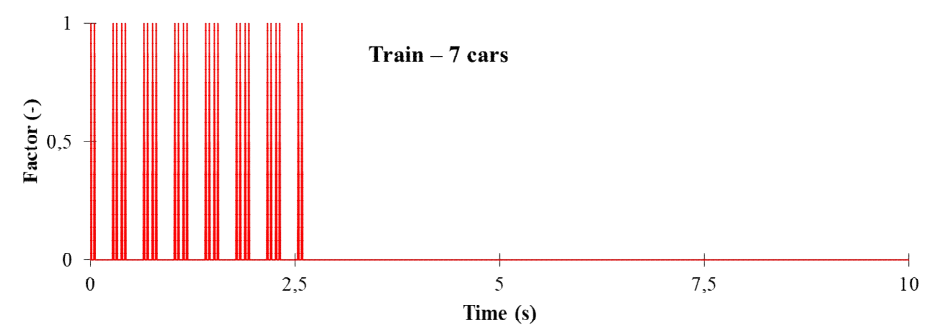

a)

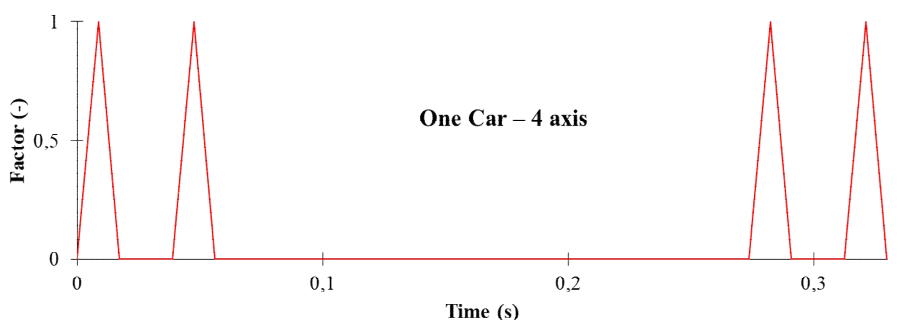

b)

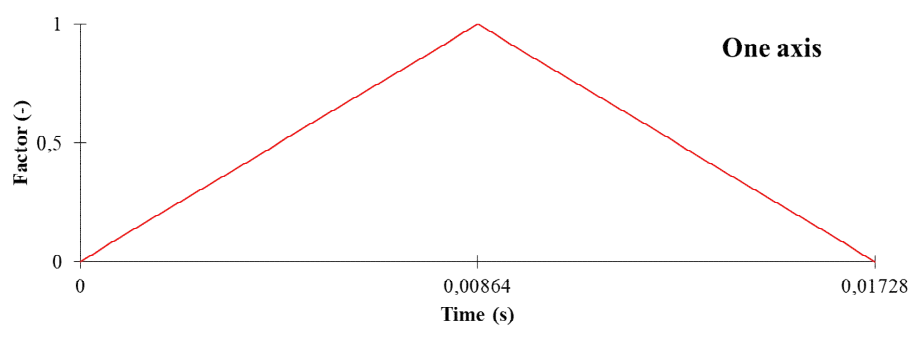

Figure 6. Vertical load curve factor - Pendolino train at a speed of $250 \mathrm{~km} / \mathrm{h}$ 


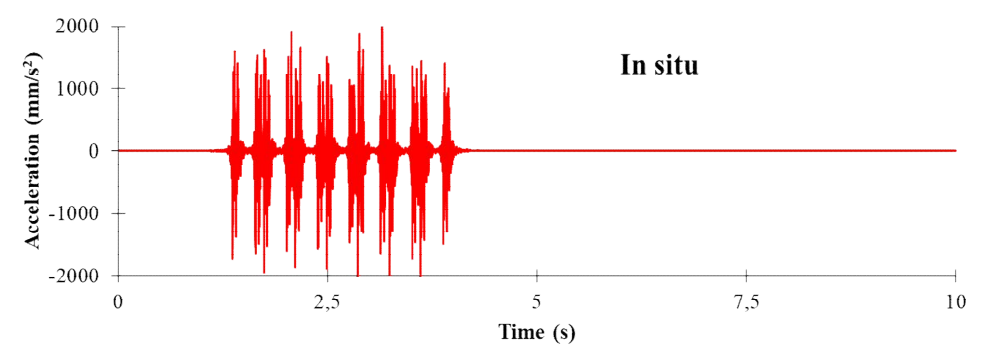

Figure 7. Acceleration of the sleepers from in situ test - Pendolino train at a speed of $250 \mathrm{~km} / \mathrm{h}$

Numerical research consisted of comparing the FFT of the horizontal and vertical vibrations recorded on the building. The analysed vibrations of the building at ground level were obtained on the basis of in situ tests and on the basis of calculations two methods of modelling vibration propagation. The first method consisted of loading the model with forces that change over time resulting from the mass of the passing train and its speed. In the second method, the measured horizontal and vertical components of the acceleration of sleeper vibrations were used. The results of the FFT amplitude recorded from in situ test acceleration and its model verification with two different approaches are presented in Figs. 8 and 9. The dominant frequencies of horizontal vibrations of the building obtained by means of the three abovementioned methods are in the range of 19 to $22 \mathrm{~Hz}$. The maximum FFT amplitudes remain in the range $1.4-2.25 \mathrm{~cm} / \mathrm{s}^{2}$ - comp. Fig. 8 .

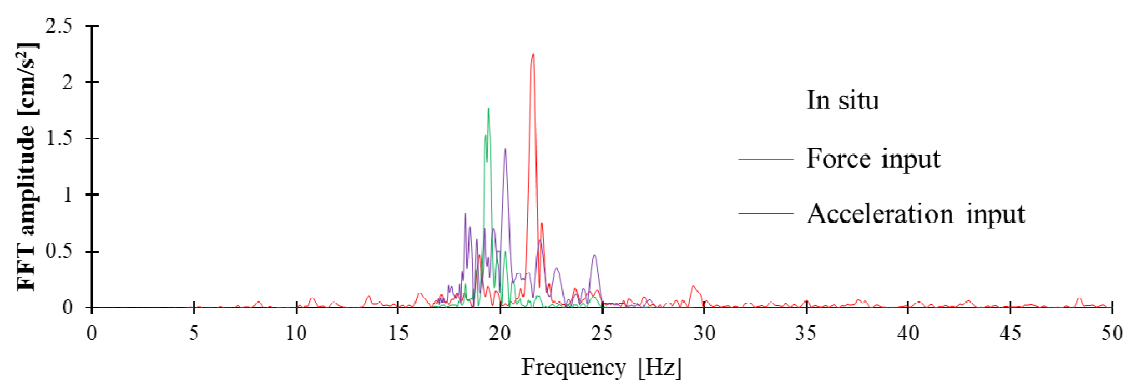

Figure 8. Comparison of FFT from in situ tests and numerical simulations - horizontal vibrations of the building at ground level

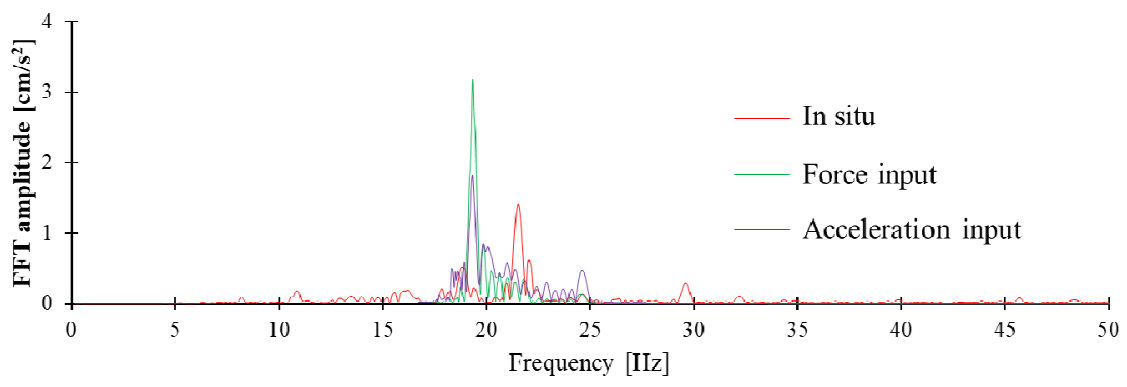

Figure 9. Comparison of FFT from in situ tests and numerical simulations - vertical vibrations of the building at ground level 
The dominant frequencies of the vertical vibrations of the building obtained by means of the two methods (force input, acceleration input) are equal $(19 \mathrm{~Hz})$. The maximum FFT amplitude obtained on the basis of force input is twice as great as in the case of acceleration input. The dominant frequency of in situ measurement is greater $(22 \mathrm{~Hz})$ and the maximum FFT amplitude is lower than amplitudes obtained by the other two methods. There are strong fits of maximum values as well as the band of dominant frequencies.

\section{Conclusions}

This study deals with the negative impact of the passage of trains on building structures. Based on the analysis of the in situ measurements and FEA simulations, we can draw the following conclusions:

- According to worldwide literature, train vibration is a growing engineering challenge, which requires more and more new means of analysis.

- The perceptibility of vibration through a structure (WODB), which refers to the scales of dynamic influences (SDI scales), formed the basis for the analysis in this paper. At the analysed speeds of up to $250 \mathrm{~km} / \mathrm{h}$, the thresholds specified by standard [16] were not exceeded.

- Propagation of vibrations from trains and their effect on nearby buildings is a complex issue. Creating a suitable FEA model for highly complex terrain conditions is a difficult task. Therefore, in situ measurements should form the basis for the construction of any FEA model.

- The creation of an appropriate vibro-isolation track design is one of the goals. The dominant frequency bands and their comparison at different speeds should be taken into account in this type of investment.

- The aim is to create increasingly improving models that present real physical phenomena. Therefore, the next papers will be targeted to the investigation of these relationships.

The authors are grateful to the Laboratory of Structural Mechanics at Cracow University of Technology. In situ investigations of vibrations were performed by the staff of the laboratory.

The authors acknowledge the support of research funded by the Ministry of Science and Higher Education - project L-4/391/2017/DS-M.

\section{References}

[1] D. P.Connolly, G. P. Marecki, G. Kouroussis, I. Thalassinakis, P. K. Woodward, Sci. Total. Environ. 568, 1276-1282 (2016)

[2] D. P. Connolly, G. Kouroussis, O. Laghrouche, C. Hoc, M. Forded, Constr. Build. Mater. 92, 64-81, (2015)

[3] T. Tatara, B. Kożuch, Procedia Engineer. 199, 2693-2698 (2017)

[4] B. Kożuch, T. Tatara, MATEC Web Conf. 107, 62 (2017)

[5] B. Kożuch, T. Tatara, E3S Web Conf. 10, 47 (2016)

[6] PN-B-02170:2016-12 Evaluation of the harmfulness of building vibrations due to ground motion (in Polish)

[7] TNO Diana 10.2 User's manual (2017)

[8] U. Basu, A. K. Chopra, Comput. Method Appl. M. 192, 1337-1375 (2002)

[9] U. Basu, A. K. Chopra, Int. J. Num. Meth. Eng. 59, 1039-1074 (2004) 